\title{
A Graduated Approach in the Abolition of Waterborne Diseases in Drinking Water Using an Indicator Based Approach and Nano Based Biosensors: A Review
}

\author{
Lucetta Marembo Wanzhen Xu \\ School of the Environment and Safety Engineering, Jiansgu University, 301 Xuefu Road, Zhenjiang, Jiangsu \\ Province, Zhenjiang 212013, China
}

\begin{abstract}
The detection of pathogens continues to be a challenge in this present day despite the advancement in technology. The emergence of waterborne diseases is of great importance and their rapid detection and identification in water is of utmost importance. Water quality indicators and pathogen detection in environmental water samples is significant for maintaining safe drinking water. Traditional methods like the culture-based methods are laborious, time consuming and yield false-positive results. Hence, a lot of research has been put in developing rapid detection methods and quantifying water pathogens in water. These methods include the use of water quality indicators as early warning systems and nano material based biosensor detection methods. The review highlights "the state of the art" method for monitoring and detecting waterborne pathogens. The review summarizes the microbiological water quality indicators and biosensor based methods. These methods are time effective, sensitive, specific and therefore important in the diagnosis and prevention of waterborne diseases.
\end{abstract}

Keywords: Waterborne Diseases, Biosensor based methods, Water quality indicators, Pathogens.

DOI: $10.7176 / \mathrm{JEES} / 10-3-07$

Publication date:March $31^{\text {st }} 2020$

\section{Introduction}

Almost 170 years later since the discovery of cholera by John Snow and the discovery of typhoid by Dr. William Budd, the world is still threatened by the provision of safe drinking water leading to the outbreak of waterborne diseases (Hrudey and Hrudey 2019). Scholars like Altintas, Gittens, Guerreiro, et al. (2015) and Altintas, Gittens, Pocock, \& Tothill (2015) assess that approximately 884 million people still lack access to safe and clean drinking water, accounting for $13 \%$ of the global population. About $90 \%$ of deaths worldwide are caused by diarrhea due to unsafe water and poor hygiene (Gall, Mariñas, Lu, \& Shisler, 2015), (Gall, Shisler, \& Mariñas, 2015). Thus, violating the United Nations goals of providing clean and safe water to all the people. Protozoa, viruses and bacteria have been identified as microorganisms of great concern. Many studies reveal that the contamination of public water supplies by human waste is the causative agent of waterborne infections but other authors have suggested that the main causal agent of recurring incidences of waterborne diseases that could have been otherwise been preventable in developed economies are because of negligence and complacency, improper assessment and monitoring of water quality (Hrudey and Hrudey 2019). Also, heavy rains may be a contributory factor in the safe provision of water. It can be argued that waterborne diseases are preventable in developed economies owing to the great advancement in technology and the economic muscle. It is evident that the issue of the provision of safe drinking water may have been overlooked or misunderstood by responsible personnel to prevent public health risk. There is need to pay more attention in the detection and identification of viruses, bacteria and parasites in water. Until recently, there has not been a comprehensive and accurate way of quantifying and detecting pathogens in several water matrices. Culture based methods have been relied on to detect pathogens in water and have been considered as "gold standard" but underlying problems exist such as the inability to detect uncultivated species, they also require lengthy time for analyzing a sample they are labor intensive (Aw and Rose 2012). The advent of biosensor based methods has brought about a tremendous paradigm shift in monitoring microbial water quality, but have their own pitfalls. To remedy these pitfalls, biosensors have been coupled with advanced materials, which are environmental friendly, low cost, effective with less energy. In the past, disinfection technology like the use of thermal treatment, chlorination and UV irradiation have been used. Scientists have developed novel methods that are promising to eliminate the incidence of waterborne diseases once and for all to ensure safe drinking water. It is evident from the past failures to prevent waterborne outbreaks that there is a need to develop proper assessment and monitoring tools that will eliminate the incidence of waterborne outbreaks. In order for us to move forward, we have to learn from our past mistakes. To quote a famous scholar "prevention is better than cure"(Gandy 2011). Preventing a disaster before it happens should be our main goal. Water indicators serve as an early warning system that water is contaminated. The aim of the work is to critically analyze the detection methods of pathogens and to assess the suitability of microbial indicators as early warning systems for water quality monitoring in wastewater treatment using developing countries as a model area. The specific objectives of this study are to assess the effectiveness of Escherichia Coli (E.Coli), total Coliforms and faecal Coliforms for water quality monitoring; and 
to analyze the use of novel materials for Biosensors as a novel method for monitoring water pathogens. It will be a revolution if we can come up with one unified method that will detect and eliminate pathogens in water bodies. This paper critically reviews the scientific data, validity and available data for and against microbiologial water quality indicaators and nano based biosensors for the detecgtion of these pathogens.

\subsection{Waterborne Diseases}

Approximately, 2.2 million annual deaths are caused by diarrhea and people who still lack access to clean and safe water account for approximately 1 billion people. (Deshmukh, Joshi et al. 2016) which the World Health Organisation (WHO) asserts that it accounts for $4 \%$ of global diseases around the World (WHO, 2011). Diseases caused by diarrheal account for more than $90 \%$ of deaths annually, it is estimated that children under the age of five and those with poor immune systems like HIV patients are more inclined to diarrhetic diseases (Deshmukh, Joshi et al. 2016, Craun 2018). It is sad to note that approximately 5000 children perish per day and this shows the seriousness of waterborne diseases. Waterborne diseases are not only a pain in the neck to the developing countries but pose an extraordinary threat to well able countries. In the past, Fecal Indicator Bacteria (FIB) has been used as the "gold standard" method for indicating waterborne diseases. For example Escherichia Coli (E.Coli) and Enterecoccus (Figueras and Borrego 2010), indicate the presence of pathogens, chemicals and bio toxins in the aqueous solution. In Zimbabwe, the Ministry of health and Child Welfare reported 1518 cholera deaths in August 2008 due to poor sanitation and contaminated water (Ahmad, Musa et al. 2019). The Bureau of Indian standards of 2012 have also reported an acute case of 10.87 million cases of acute gastroenteritis, resulting mostly from viral and bacterial pathogens like hepatitis A and B, salmonella spp, shigella spp, and Escherichia Coli. Waterborne diseases fall under 3 categories namely Viruses, parasites and bacteria. Table 1 summarizes some of the most dangerous diseases caused by waterborne pathogens. Some of these diseases are persistent in water and most of the microbes in drinking water do not pose threat to humans. However, Howe (2002) says that the outbreak of diseases may arise due to poor treatment methods. Some pathogens withstand disinfection methods leading to the formation of bio films which persist in water distribution systems (Figueras and Borrego 2010).In the United States of America, Campylobacter and Legionella are the number one leading agents of waterborne diseases (Yoder ,2011). According to the guidelines stipulated by WHO and the United States Environmental Protection Agency (USEPA), the presence of E. Coli and total coliforms should be very scarce in any $100 \mathrm{ml}$ of drinking water. Water contaminated by feces of contaminated animals and mankind lead to the contamination of reservoirs (Connelly and Baeumner 2012). Waterborne pathogens that are persistent in low numbers may be diluted in the water, thus making it difficult to enumerate and detect. Hence, the monitoring and detection of pathogens plays a pivotal role in the prevention and mitigation of waterborne outbreaks. In this review, we will be dealing with recent microbial indicators and the latest developments of biosensor based methods, their advantages, limitations, applicability and enumeration.

Table 1: Examples of waterborne pathogens, their related diseases and routes (modified from (Connelly and Baeumner 2012).

\begin{tabular}{|c|c|c|c|}
\hline $\begin{array}{l}\text { Pathogen } \\
\text { type }\end{array}$ & Example of the microbe & Associated symptoms & Route \\
\hline Viruses & $\begin{array}{l}\text { Norovirus } \\
\text { Hepatitis A } \\
\text { Hepatitis B } \\
\text { Rotavirus } \\
\text { Adenovirus } \\
\text { Astrovirus }\end{array}$ & $\begin{array}{l}\text { Viral gastroenteritis } \\
\text { Infectious hepatitis } \\
\text { Viral hepatitis } \\
\text { Acute gastroenteritis } \\
\text { Gastroenteritis } \\
\text { Diarrhoea }\end{array}$ & $\begin{array}{l}\text { Drinking Contaminated } \\
\text { faecal water }\end{array}$ \\
\hline Bacterias & $\begin{array}{l}\text { Mycobacteria spp } \\
\text { Vibrio Cholerae } \\
\text { E. Coli } \\
\text { Legionella } \\
\text { Pneumonia } \\
\text { Aeromonas spp } \\
\text { Campylobacter jejul }\end{array}$ & $\begin{array}{l}\text { Pulmonary disease } \\
\text { Cholera } \\
\text { Gastroenteritis } \\
\text { Legionnaires'disease,poatiac fever } \\
\text { Wound infections,respiratory tract } \\
\text { infections } \\
\text { Gastroenteritis }\end{array}$ & $\begin{array}{l}\text { Drinking Contaminated } \\
\text { food and water } \\
\text { Lack of proper sanitation } \\
\text { of water }\end{array}$ \\
\hline Protozoa & $\begin{array}{l}\text { Giardia lumblia } \\
\text { Acanthamoeba spp. } \\
\text { Naeglera fowleri } \\
\text { Cryptosporidiamparvion }\end{array}$ & $\begin{array}{l}\text { Diarrhoea } \\
\text { Gramulomateos anoebic } \\
\text { Encephalitis } \\
\text { Diarrhoea }\end{array}$ & $\begin{array}{l}\text { Drinking contaminated } \\
\text { water }\end{array}$ \\
\hline Fungi & $\begin{array}{l}\text { Fusarian Solani } \\
\text { Aspergillus Fumigates }\end{array}$ & $\begin{array}{l}\text { Skin related disease } \\
\text { Respiratory illnesses }\end{array}$ & Contaminated water. \\
\hline
\end{tabular}




\subsection{Microbiological Water Qality Indicators}

Faecal contamination is an important cause of waterborne diseases and has resulted in several thousand mortalities around the world. The indicators mostly used to determine faecal pollution are bacterial but unfortunately the water also contains viruses and protozoa (Horan 2003).As a result this has caused this indicator organism to be questioned in their effectivess to detect viruses and protozoas in water and to measure water quality. Therefor there is need to add more indicators that will be able to not only detect bacteria in water bodies but can also detect viruses and protozoa. Several indicators have been proposed to serve as early warning systems for the detection of waterborne diseases. The potential value of different groups water indicators has been studied in depth and reviewed. Achieving microbiological safe drinking water in many communities and around the world still remains an obstacle due to a number of factors such as lack of field analysis test kits and lack of acces to laboratories.In an effort to overcome these challenges,several indicators have been proposed to detect water pathogens. Some of these proposed indicator methods and their tests have low cost, they are simple to use and do not require any field test or laboratory testing.

Over the century, the indicator organism approaches have been relied on to assess the microbiological water quality. Using microbiological indicators to detect faecal contamination has been proven to be the fastest reported to date. The most common water quality indicator used is the Escherichia Coli (E.Coli), total Califorms and faecal Coliforms. However, the dependence on these organisms to determine water quality is still under review. Many waterborne pathogens are present at extremely low concentrations and thus challenging to detect. Common waterborne diseases include diarrhoea, schistomasis and trachena. It is obligatory for current water management systems to test the presence of E. Coli. The adoption of disinfection practices by Drinking Water Utilities has drastically decreased the incidence of waterborne illnesses.

\subsection{Total coliforms and faecal coliforms}

Total Coliforms and Faecal coliforms were used as a substitute for E. coli to detect faecal pollution. The detection of total coliforms provides the relevant government with information on any changes in water quality. The membrane filtration and the most probable numbers (MPN) are the classical technologies used to detect total and faecal Coliforms (Patnaik 2017). The tests are simple and easy to flow but the process is time consuming. It requires at least 48 hours to get the credible results and the results do not allow for the detection of all the targeted bacteria in the natural environment (Lin \& Ganesh, 2013; Ganesh \& Lin, 2013). Other scholars have argued that since coliforms are capable of growth in water bodies and the environment, they cannot be relied on as indicators of water quality (Rusin, Rose, Haas, \& Gerba, 1997; LeChevallier, 1990; Camper, McFeters, Characklis, \& Jones, 1991). According to Who \& Consultation (2003) coliforms are still acceptable as water quality indicators even though there are some disadvantages in using this method. The discovery of coliforms in drinking water may be an indication of a failure in the treatment process and this may have serious repercussions on public health. The use of E. Coli as a water quality indicator has got its advantages and limitations. E. Coli has constantly been detected in larger proportions in the faeces of humans and animals. Presently, over 160 water pathogens, of which the relative quantity are not pathogenic to humans (Salyers, Whitt, \& Whitt, 1994). According to Tallon, Magajna, Lofranco, \& Leung (2005) E. Coli is the only exclusive Coli form almost associated with a faecal source. In a report by Hung, Huang, Huang, Huang, \& Chang (1997) the presence of the $\beta$-galactosidase enzyme makes detection methods more reliable, sensitive, simple and rapid. Presently, the best method for the detecting waterborne illnesses in drinking water is E. Coli. However, E. Coli is not only as a result of direct faecal pollution, but can take place as result of unsafe handling and improper storage and leakages. Other studies suggest that E. Coli may be found at high concentration in waste material from pulp and paper mills as well as in natural water system (Lopez-Torres, Hazen, \& Toranzos, 1987). Another flaw in using this method is that it has no specificity in indicating some specific enteric pathogens such as protozoa and viruses. Using E.coli as an indicator for pathogens is inexpensive and easy to detect, however, they do not correlate with other pathogens in the water system like viruses and helminths, and they also do not provide full information of their host origin (RamírezCastillo et al., 2015). Water that has been declared free of E. Coli may still contain viruses and protozoa.

\subsection{Phages of bacteria as novel methods for water quality indicator}

Due to the less effectiveness of current water quality indicators at determining the potential risk of waterborne illnesses to public health, the phages of Bacteriodes have emerged as a novel tool for the assessment of the presence of human specific phages using a low cost microbial source tracking (MST) (Ebdon, Sellwood, Shore, \& Taylor, 2011). Wildly used methods such as those based on faecal indicator bacteria (FIB) for determining water quality have proved not to correlate with the presence or absence of pathogens. The waters that have classified as "acceptable" under FIB have been responsible for viral diseases such as hepatitis and gastroenteritis (Ebdon et al., 2011). In an experiment conducted by Perez-Mercado et al. (2019) \& Cossio et al. (2019) it was concluded that bacteriophages can be used as a substitution for viruses. Phages are rapid, easy to analyze and non pathogenic to humans. Phages have also demonstrated good endurance in a laboratory environment. Phages possess many 
inherent properties notably, size, morphology, composition and site of replication. They are also resistant against environmental factors compared to FIB. The phages resemble those of human more closely than other bacterial indicators used (Lin \& Ganesh, 2013; Ganesh \& Lin, 2013). The major groups of phages used for water quality assessment consist of somatic coliphages and F-Specific RNA (Skraber, Gassilloud, \& Gantzer, 2004; Skraber, Gassilloud, Schwartzbrod, \& Gantzer, 2004). There is more data on the incidence of somatic phages in water environments as they are more efficient than others in hosting phages and they are detectable by inexpensive and simple ,rapid techniques. They are found in large numbers in waste water, and polluted water. They may also be duplicated by the host bacteria in the environment. However, it is still questionable whether somatic phages can be reliable in detecting viral contamination of surface waters. According to the works done by Kott, Roze, Sperber, \& Betzer, (1974) and Fannin, Gannon, Cochran, \& Spendlove (1977). They are considering phages as good indicators for viral contamination of water bodies, but on the other had some scholars have made a conclusion that somatic phages are not the most reliable factor for anticipating waterborne viruses.

\subsection{Pepper Mild Mottle Virus (PMMov)}

Since Viruses are not easy to detect using traditional indicators like E Coli and Enteroccci owing to their availability in low concentrations $\left(<10^{5}\right.$ copies per litre).Pepper Mild Mottle Virus (PMMov) has emerged as the state of the art novel indicator for the identification of faecal pollution. PMMov offers several advantages over the FIB indicators like E.Coli and somatic phages. Firstly, PMMov is available in great quantities in domestic water $\left(10^{10}\right.$ PMMov copies per litre). Secondly, PMMov has not been detected in waters free of fecal contamination like FIBs and is found in humans and not animals. Consequently, the use of PMMov as a water quality indicator needs further research (Symonds, Rosario et al. 2019).

\section{Detection of waterborne diseases \\ 2.1 Biosensor Technology}

Currently, the diagnostics of viruses is more challenging than diagnosing other pathogens like bacterias and protozoa. Hence, many technologies have been limited in their detection of viruses due to their small size. The other challenge faced in the detection viruses is that they have RNA genomes instead of DNA which are dynamic ,more complex and genetically variable (Altintas, Gittens et al. 2015). Convetional traditional methods like polymarase chain reaction (PCR), enzyme immunoassays and immunofourescence microscopy are becoming outdated in the detection of waterborne diseases (Connelly and Baeumner 2012).Currently the most used detection technique is the Nucleic acid amplification techniques such as PCR and real -time PCR. These methods can gather epidemilogical informationsuch as genotype data. The advantage of using PCR is that it saves resources and time and detects the virus within a single step.However, this technique is hampered by their high cost due to their need for expensive staff and specialist equipment (Altintas, Gittens et al. 2015). Another limitation is that they will give inaccurate results analysis if the analyte concentration sample is at a critical low level. Currently, the detection methods of pathogens are slow and inefficient especial in regions where technology and resources are limited therefore, there is need to develop methods that are easy to use and inexpensive and do not require complicated assay times. Conventional methods like the culture based methods are labor intensive and inherently time consuming. Furthermore, in culture based methods the spectrum of pathogens reduces their sensitivity to detect pathogens leading to serious health care problems (Seng et al., 2013; Fournier et al., 2013). In order to overcome these problems there is need to develop a novel detection that is sensitive, coupled with high sensitivity, high selectivity and speed and cost effective. Biosensors enhanced with nano technology have been developed to enhance detection methods and they offer various advantages over conventional methods including label free detection, real time analysis, reduced limit of detection and it requires small sample volume to mention but a few (Fournier et al., 2013). Biosensors show great promise in meeting the needs of analytical methods. Pathogen detecting Biosensors have been developed using nuclear magnetic resonance (NMR) (Harel, Schröder, \& Xu, 2008), electrical , mechanical, electro chemical and optical sensing methods. A Biosensor is a device that uses antibodies or enzymes to detect the presence of an analyte (Altintas, Gittens, Guerreiro, et al., 2015; Altintas, Gittens, Pocock, et al., 2015). There are three forms of biosensors namely: optical, electrical, and mass sensitive. Figure 1 shows the main components of a biosensor. Biosensors are made up of a bio receptor which comprises of a microorganism,cells or antibody ; a transducer for sending the physicochemical signal; and a signal processor that converts the information into data. A biosensor requires the selection of the receptor able to selectively and sensitively detect the targetted analyte .The receptor is then applied on the surface of the transducer to complete the device. Recognition receptors that have been applied successful include Molecuarly imprinted polymers (MIPs), antibodies and aptamers (Justino, Duarte et al. 2017).Therefore, succesful incopration of these receptors is of utmost importance in the operation of the biosensor. Biosensors still need to overcome the hurdles of sample time preparation, sensitivity to sample matrix and system intergration.. To achieve rela time biosensors, nano particles or smart materials like DNA can be implemented which has been applied in clinical diagnostics of patieents with HIV (Zhao, Wong et al. 2019). Biosensor systems are more favored due to its ease of use and its 
capability to carry out an analsyis on site. Biosensors in tandem with biosensors can lead to the simultaneos analysis of samples in real time. However, the commercialization of biosensors is still a challenge but its market is projected at an annual rate of $25 \%$ in the future (Suryan 2017).

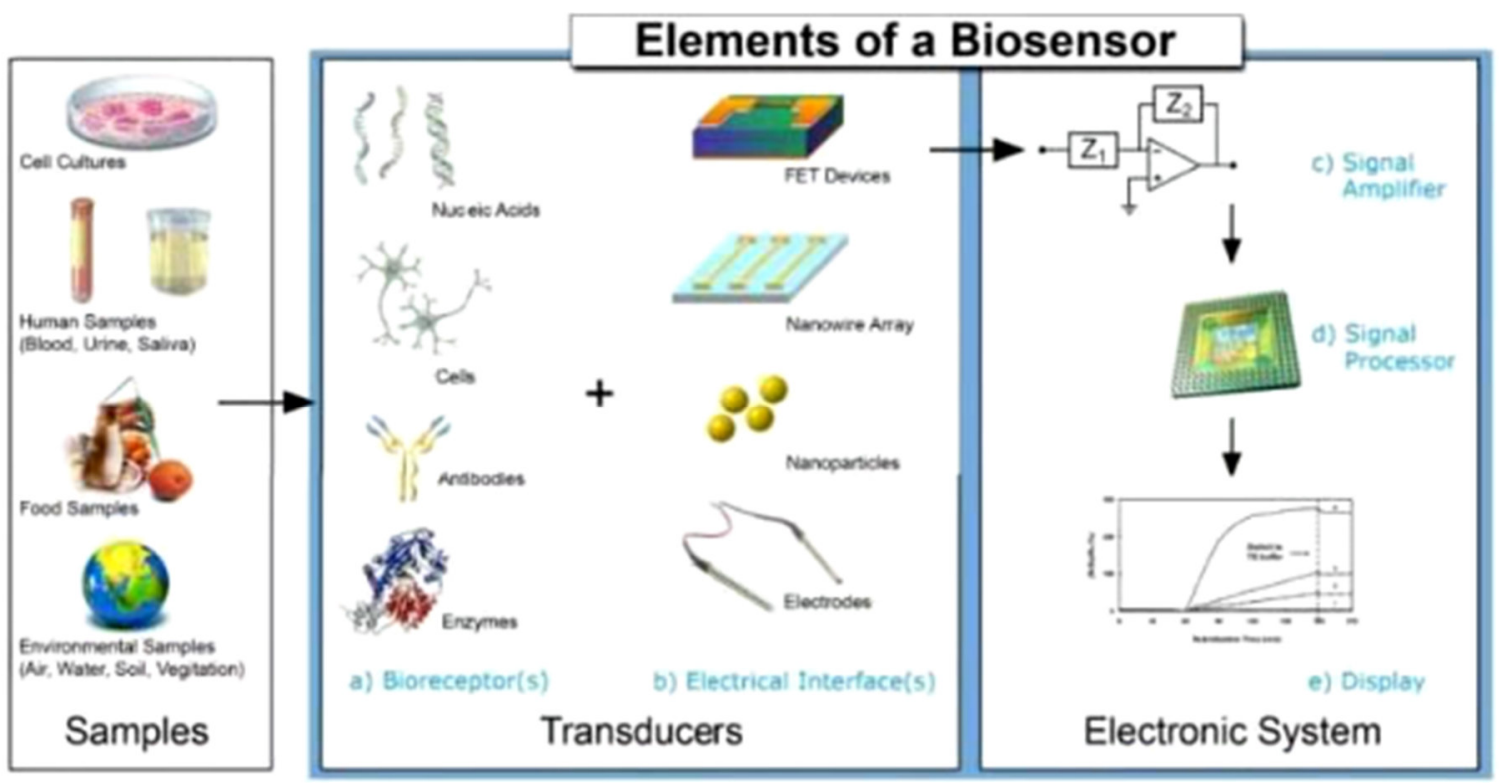

Figure 1 Elements of a biosensor

2.1.1 Optical biosensor

Optical biosensors are gaining momentum in the field of sensors. Various optical biosensors have been developed to detect pathogens like the colorimetric biosensors which are cost effective, easy to use and offer rapid diagnosis within 15 minutes and plasmonic biosensors which offer complex capability and superior sensitivity (Yoo \& Lee, 2016). The advantages that the optical biosensors compared to conventional methods have led to the development of more ingenious optical sensors of which some of them are available in the market. Additional, microfluidic optical sensors are currently under commercialization and ready to be launched by companies like LAMDAGEN. Optical sensors will have an increasing role in the monitoring of environmental and clinical settings. The following section will highlight some crucial optical sensors that have been applied for the detection of pathogens.

2.1.1.1 Colorimetric biosensors

They are an attractive optical biosensor because they are easy to observe pathogenic microorganisms in the sample with the naked eye. There is also no need for any analytical instruments through a color change in the sample (Connelly \& Baeumner, 2012). There are two types of colometric biosensors, namely the flat substrate based and solution based (Yoo and Lee 2016). Flat substrate sensors use paper and glass and they are generally preferred because there are simple to use and require a small sample volume. An example of a flat substrate sensor is the Lateral Flow Assay (LFA), which is currently available in the market place produced by DuPont Co. The LFA can detect salmonella, Escherichia Coli and Listeria within in 10 min using antibodies (Yoo and Lee 2016). Among all colorimetric methods, the best method is the loop -mediated isothermal amplification (LAMP) owing to its low price and affordability, higher efficiency and faster detection time and also it offers reproducible results.However, nanoparticle based biosensors are far much superior in the detection of pathogens onsite (Zhao, Wong et al. 2019). Nano particle colorimetric biosensors couple with LAMP have proven to be highly sensitive for detecting waterborne diseases on site (Zhao, Wong et al. 2019). The Loop mediated isothermal amplification (LAMP) was developed by Notomi in 2000 for detecting DNA. Because of it swiftness and simplicity this method can be used in developing economies / rural areas (Mori and Notomi 2019). LAMP is a fast, effective, simple detection method using DNA and it does not require any lab equipment. The results are accurate and can be repeated. The major advantage of using LAMP method is that it uses one single step test tube for approx. 30 mins at around $60-65$ degrees.The reaction time is very fast at just 10 mins (Zhao, Wong et al. 2019). However, the LAMP method is too sensitive and this can lead it to yield false results and risk cross contamination during the experiment .Recent studies have proven that biosensors can be coupled with nano materials to make them more efficient and versatile.Among these nano materials ,quantum dots and silver nanoparticles have been proposed. Quantum dots are semi conducting nano particles and they are flourescent and they have a lot of applications in the detection of waterborne dieases specifically viruses. Quantum dots are modified and used with other nano materials to detect viruses in water by observing color change . 


\subsubsection{Electrical Biosensors}

Electrical Biosensors have the ability to overcome problems the potential to reduce false negative results and low sensitivity. Nano technology offers a great promise to overcome the obstacles of electrical biosensors. For example, studies reported in the 1990s amperometric biosensors for E. Coli were achieved in a LOD $10^{3}-10^{4}$ cells $/ \mathrm{ml}$ after $3 \mathrm{~h}$ pre-enrichment (Bridle, Balharry et al. 2015). Recently, liposome coated carbon nanotubes have been used to detect cholera toxin with an LOD of $10^{-16 \mathrm{~g}}$ (Bridle, Balharry et al. 2015). Carbon nanotubes coated with $\mathrm{Fe}_{3} \mathrm{O}_{4}$ have been applied for the rapid detection of coliforms. The above examples show how electrical biosensors have been used in pathogen detection, particularly E. Coli which has used different types of nanomaterials (NMs). There is a likelihood that the above technology may be applicable to other types of pathogens. In another study by Liu et al. Graphene based electrochemical biosensors were highly sensitive in the detection of pathogens. To further add on, electrochemical sensors were developed using DNA aptamers and it was modified using multi-wall carbon nanotubes (MWNT), gold nanoparticles (GNPs) and pollypyrole nanowires (PPNWs) to increase sensititivity and selectivity. This electrode provided a highly electrocatalyic activity, a porous structure with a large surfacearea that is effective. This hybrid nanomaterial (MWNT | GNPs| PPNWs) reached a detection limit of $4.3 \times 10^{-13}$ showing that it be used to fabricate electrochemical bionsesors for detecting analytes (Vigneshvar, Sudhakumari et al. 2016).

\subsubsection{Mass Sensitive Based Biosensors}

For water quality monitoring, mass sensitive biosensors have been mainly used for the detection of bacteria, particularly E. Coli. Novel materials have been used to aid in the detection of bacteria using cantilivers, surface plasmon resonance (SPR) and quartz crystal microbalance (QCM) (Bridle, Balharry, Gaiser, \& Johnston, 2015). Surface Plasmon (SPR) has been constricted by their inconsistency to measure small changes in refractive indexes. To solve this problem novel materials like liposomes and dendrimers have been applied to modify the detection of E.Coli and Cryptosporidium thus achieving the simultaneous detection of pathogens (Bridle, Balharry et al. 2015). The use of silicon nitride cantilivers have been used to monitor salmonella enterica bacteria. The cantilivers surface bends when in contact with bacteria and the surface bending of the cantiliver expose the amount of bacteria present (Bridle et al., 2015). Generally, a couple of biosensors have been unreported for virus detection. Mass sensitive is mostly used for the detection of protozoa. Nanotechnology can improve the procedure of mass sensitive biosensors but there is need for more research in the detection of protozoa. In future, studies should focus on reducing detection times and assay times and to also focus on samples of unknown concentration.

\section{Conclusion}

Numerous methods have been developed to detect pathogens in water bodies, yet no single method seems to be entirely effective in the abolishing of waterborne diseases. Therefore, it is important to monitor viruses, bacterias and protozoa to better understand their prevalence. The use of bacteria as a measure for water quality has raised some doubts over the years to determine water quality and to predict the presence of pathogens. Owing to the fact that water not only contains bacterias but also viruses and protozoas. The water that would have been otherwise declared free of bacteria may be inhabitted by viruses and protozoa.Hence the need to have some additonal indicators that will allow for the detection of both bacteria,protozoa and viruses. The indicator based approach is still applicable and efficient in the eradication and detection of waterborne pathogens. Fecal indicators have been used to measure any possible risk to the exposed population. Additional water quality indicators like somatic phages show promising potential due to their cost effectiveness, speed and reproducibility In this study, it is clear that we need to come up with improved water quality indicators to aid in water monitoring. However, it recommended that we add virological monitoring to ameliorate water quality monitoring. Amongst these, bacteriophages have shown great potential as an index organism owing to its abundance in fecal contaminated water.Their detection in water bodies is simple ,cheap and reasonable robust. The use of total coliforms and fecal coliforms as indicators is also a promising approach because the tests are simple and easy to flow but the process is time consuming. Pepper Mild Mottle Virus (PMMov) has emerged as the state of the art novel indicator for the identification of faecal pollution. PMMov is the first indicator that can effectively detect viruses in water. Also the PMMov can differentiate the source of contamination whether its human or animal.But further research is still needed for its application on the field. The detection of pathogens is essential in the abolishing of waterborne diseases.Conventional methods like RT-PCR and PCR are not so favorable as they are time consuming and laborious and may yield false results. The major setback is their need for trained personnel and expensive lab instruments. Recent investigations on biosensors have revealed that biosensors are gaining momentum in the field of environment .Biosensors have been used in the medical field, food industry and environment.They are highly attractive for the prevention of pandemics. Biosensors are an attractive choice owing to their rapid and ease of use and they do not require trained professionals. To add on, the biosensor based method can be used to quantify and quantify waterborne diseases in drinking water.The application of nanomaterials such as quantum dots, gold nanoparticles and carbon nanotubes in biosensors has enhanced its capacity and and sensitivity. The use of nanomaterials for the detection of pathogens will have be a major revolution in the field of environment, health 
care, food and agriculture.It is recommended that we develop technologies that will allow for the in-situ analysis of pathogens, a technology that will allow for the simultaneous detection of pathogens in water bodies.

\section{Acknowledgement}

Our gratitude is extended to the School of the Environment and safety Engineering in Jiangsu University, China.

\section{Conflict of interest}

Authors declare no conflict of interest.

\section{References}

Ahmad, T., Musa, T. H., Wei, P., \& Jin, H. (2019). Cholera outbreak in Zimbabwe 2018. Southern African Journal of Public Health (incorporating Strengthening Health Systems), 3(2), 31.

Aldieri, L., Carlucci, F., Vinci, C. P., \& Yigitcanlar, T. (2019). Environmental innovation, knowledge spillovers and policy implications: A systematic review of the economic effects literature. Journal of Cleaner Production, 118051

Altintas, Z., Gittens, M., Guerreiro, A., Thompson, K.-A., Walker, J., Piletsky, S., \& Tothill, I. E. (2015). Detection of waterborne viruses using high affinity molecularly imprinted polymers. Analytical chemistry, 87(13), 6801-6807.

Altintas, Z., Gittens, M., Pocock, J., \& Tothill, I. E. (2015). Biosensors for waterborne viruses: Detection and removal. Biochimie, 115, 144-154.

Ardoin, N. M., Bowers, A. W., \& Gaillard, E. (2019). Environmental education outcomes for conservation: A systematic review. Biological Conservation, 108224.

Aw, T. G., \& Rose, J. B. (2012). Detection of pathogens in water: from phylochips to qPCR to pyrosequencing. Current Opinion in Biotechnology, 23(3), 422-430.

Bridle, H., Balharry, D., Gaiser, B., \& Johnston, H. (2015). Exploitation of nanotechnology for the monitoring of waterborne pathogens: State-of-the-art and future research priorities. Environmental science \& technology, 49(18), 10762-10777.

Camper, A. K., McFeters, G. A., Characklis, W. G., \& Jones, W. L. (1991). Growth kinetics of coliform bacteria under conditions relevant to drinking water distribution systems. Appl. Environ. Microbiol., 57(8), 2233-2239.

Connelly, J. T., \& Baeumner, A. J. (2012). Biosensors for the detection of waterborne pathogens. Analytical and bioanalytical chemistry, 402(1), 117-127.

Cossio, C., Perez-Mercado, L. F., Norrman, J., Dalahmeh, S., Vinnerås, B., Mercado, A., \& McConville, J. (2019). Impact of treatment plant management on human health and ecological risks from wastewater irrigation in developing countries-case studies from Cochabamba, Bolivia. International journal of environmental health research, 1-19.

Craun, G. F. (2018). Waterborne Diseases in the US: CRC Press.

Deshmukh, R. A., Joshi, K., Bhand, S., \& Roy, U. (2016). Recent developments in detection and enumeration of waterborne bacteria: a retrospective minireview. MicrobiologyOpen, 5(6), 901-922.

Ebdon, J. E., Sellwood, J., Shore, J., \& Taylor, H. D. (2011). Phages of Bacteroides (GB-124): a novel tool for viral waterborne disease control? Environmental science \& technology, 46(2), 1163-1169.

Fannin, K., Gannon, J. J., Cochran, K. W., \& Spendlove, J. (1977). Field studies on coliphages and coliforms as indicators of airborne animal viral contamination from wastewater treatment facilities. Water Research, 11(2), 181-188.

Figueras, M., \& Borrego, J. J. (2010). New perspectives in monitoring drinking water microbial quality. International journal of environmental research and public health, 7(12), 4179-4202.

Fournier, P.-E., Drancourt, M., Colson, P., Rolain, J.-M., La Scola, B., \& Raoult, D. (2013). Modern clinical microbiology: new challenges and solutions. Nature Reviews Microbiology, 11(8), 574-585.

Frank, J. J., Poulakos, A. G., Tornero-Velez, R., \& Xue, J. (2019). Systematic review and meta-analyses of lead $(\mathrm{Pb})$ concentrations in environmental media (soil, dust, water, food, and air) reported in the United States from 1996 to 2016. Science of The Total Environment.

Gall, A. M., Mariñas, B. J., Lu, Y., \& Shisler, J. L. (2015). Waterborne viruses: a barrier to safe drinking water. PLoS pathogens, 11(6), e1004867.

Gall, A. M., Shisler, J. L., \& Mariñas, B. J. (2015). Analysis of the viral replication cycle of adenovirus serotype 2 after inactivation by free chlorine. Environmental science \& technology, 49(7), 4584-4590.

Gandy, S. (2011). Perspective: prevention is better than cure. Nature, 475(7355), S15.

Ganesh, A., \& Lin, J. (2013). Waterborne human pathogenic viruses of public health concern. International journal of environmental health research, 23(6), 544-564.

Harel, E., Schröder, L., \& Xu, S. (2008). Novel detection schemes of nuclear magnetic resonance and magnetic resonance imaging: applications from analytical chemistry to molecular sensors. Annu. Rev. Anal. Chem., 1, 
133-163.

Horan, N. J. (2003). Faecal indicator organisms. The handbook of water and wastewater microbiology, 105-112.

Hrudey, S., \& Hrudey, E. (2019). Common themes contributing to recent drinking water disease outbreaks in affluent nations. Water Supply.

Hung, C.-H., Huang, H.-R., Huang, C.-J., Huang, F.-L., \& Chang, G.-D. (1997). Purification and cloning of carp nephrosin, a secreted zinc endopeptidase of the astacin family. Journal of Biological Chemistry, 272(21), 13772-13778.

Justino, C. I., Duarte, A. C., \& Rocha-Santos, T. A. (2017). Recent progress in biosensors for environmental monitoring: A review. Sensors, 17(12), 2918.

Kott, Y., Roze, N., Sperber, S., \& Betzer, N. (1974). Bacteriophages as viral pollution indicators. Water research, $8(3), 165-171$.

LeChevallier, M. W. (1990). Coliform regrowth in drinking water: a review. Journal-American Water Works Association, 82(11), 74-86

Lin, J., \& Ganesh, A. (2013). Water quality indicators: bacteria, coliphages, enteric viruses. International journal of environmental health research, 23(6), 484-506.

Lopez-Torres, A. J., Hazen, T. C., \& Toranzos, G. A. (1987). Distribution and in situ survival and activity ofKlebsiella pneumoniae andEscherichia coli in a tropical rain forest watershed. Current Microbiology, 15(4), 213-218.

Mori, Y., \& Notomi, T. (2019). Loop-mediated isothermal amplification (LAMP): Expansion of its practical application as a tool to achieve universal health coverage. Journal of Infection and Chemotherapy.

Patnaik, P. (2017). Handbook of environmental analysis: chemical pollutants in air, water, soil, and solid wastes: Crc Press.

Perez-Mercado, L. F., Lalander, C., Joel, A., Ottoson, J., Dalahmeh, S., \& Vinnerås, B. (2019). Biochar filters as an on-farm treatment to reduce pathogens when irrigating with wastewater-polluted sources. Journal of environmental management, 248, 109295.

Ramírez-Castillo, F. Y., Loera-Muro, A., Jacques, M., Garneau, P., Avelar-González, F. J., Harel, J., \& GuerreroBarrera, A. L. (2015). Waterborne pathogens: detection methods and challenges. Pathogens, 4(2), 307-334.

Rusin, P. A., Rose, J. B., Haas, C. N., \& Gerba, C. P. (1997). Risk assessment of opportunistic bacterial pathogens in drinking water Reviews of environmental contamination and toxicology (pp. 57-83): Springer

Salyers, A. A., Whitt, D. D., \& Whitt, D. D. (1994). Bacterial pathogenesis: a molecular approach (Vol. 3): ASM press Washington, DC.

Seng, P., Abat, C., Rolain, J. M., Colson, P., Lagier, J.-C., Gouriet, F., . . Raoult, D. (2013). Identification of rare pathogenic bacteria in a clinical microbiology laboratory: impact of matrix-assisted laser desorption ionization-time of flight mass spectrometry. Journal of clinical microbiology, 51(7), 2182-2194.

Skraber, S., Gassilloud, B., \& Gantzer, C. (2004). Comparison of coliforms and coliphages as tools for assessment of viral contamination in river water. Appl. Environ. Microbiol., 70(6), 3644-3649.

Skraber, S., Gassilloud, B., Schwartzbrod, L., \& Gantzer, C. (2004). Survival of infectious Poliovirus-1 in river water compared to the persistence of somatic coliphages, thermotolerant coliforms and Poliovirus- 1 genome. Water research, 38(12), 2927-2933.

Suryan, S. K. (2017). Biosensors: a tool for environmental monitoring and analysis Advances in Environmental Biotechnology (pp. 265-288): Springer.

Symonds, E. M., Rosario, K., \& Breitbart, M. (2019). Pepper mild mottle virus: Agricultural menace turned effective tool for microbial water quality monitoring and assessing (waste) water treatment technologies. PLoS pathogens, 15(4), e1007639.

Tallon, P., Magajna, B., Lofranco, C., \& Leung, K. T. (2005). Microbial indicators of faecal contamination in water: a current perspective. Water, air, and soil pollution, 166(1-4), 139-166.

Who, J., \& Consultation, F. E. (2003). Diet, nutrition and the prevention of chronic diseases. World Health Organ Tech Rep Ser, 916(i-viii).

Vigneshvar, S., Sudhakumari, C., Senthilkumaran, B., \& Prakash, H. (2016). Recent advances in biosensor technology for potential applications-an overview. Frontiers in bioengineering and biotechnology, 4, 11 .

Yoo, S. M., \& Lee, S. Y. (2016). Optical biosensors for the detection of pathogenic microorganisms. Trends in biotechnology, 34(1), 7-25.

Zhao, V. X. T., T. I. Wong, X. T. Zheng, Y. N. Tan and X. Zhou (2019). "Colorimetric Biosensors for Point-ofCare Virus Detections." Materials Science for Energy Technologies. 